\title{
Strong paper from spruce CTMP - Part II: Effect of pressing at nip press temperatures above the lignin softening temperature
}

https://doi.org/10.1515/npprj-2018-3009

Received August 17, 2017; accepted January 2, 2018; previously published online February 25, 2018 on www.npprj.se

\begin{abstract}
The main objective of the current study was to demonstrate that it is possible to enhance strength properties of sheets from spruce HT-CTMP and CTMP furnishes up to the same level as is common on sheets from softwood kraft pulps by changing conditions in papermaking. To achieve that, sheets of spruce HT-CTMP and CTMP were consolidated at densities close to that of the reference bleach kraft pulp by pressing at press nip temperatures well above the tack and softening temperatures of lignin. On sheets from spruce CTMP (CSF $420 \mathrm{ml}$ ), where the fibers were surface treated with cationic starch, it was possible to reach tensile index at the same level as on sheets from the untreated reference kraft pulp. The compression strength (SCT) of CTMP and HT-CTMP sheets, which were achieved at the highest press nip temperature $\left(200^{\circ} \mathrm{C}\right)$ in the study, was equal to or higher than that of the reference kraft pulp sheets. The results show that there is a great yet unexploited potential in papermaking from spruce HT-CTMP and CTMP furnishes, which could be utilized in manufacturing of products where very high requirements upon strength is demanded.
\end{abstract}

Keywords: adsorption; CMC; CTMP; heat; polyelectrolytes; pressure; starch; tensile index.

\section{Background}

The characteristic properties of softwood chemimechanical pulps (CTMP) are of special interest in manufacturing of high quality packaging board as this type of high yield pulps (HYP) can be formed in sheets with a higher bulk at a given internal bond strength than

\footnotetext{
*Corresponding author: Sven Norgren, Mid Sweden University, SE-851 70 Sundsvall, Sweden, e-mail: sven.norgren@miun.se Gunilla Pettersson, Hans Höglund, Mid Sweden University, SE-851 70 Sundsvall, Sweden, e-mails: gunilla.pettersson@miun.se, hans.hoglund@miun.se
}

sheets from chemical pulps (Bengtsson 2005, Fineman 1985, Höglund and Wilhelmsson 1992). This advantage can above all be utilized in multi-layered packaging board where bending stiffness is improved substantially, when outer plies are manufactured with high in-plane strength and tensile stiffness in combination with a bulky middle ply with stiff CTMP fibers as a main component (Bengtsson 2005, Fineman 1985, Höglund and Wilhelmsson 1992, Fellers et al. 1983). This design is especially advantageous in manufacturing of paperboard with low basis weight. The relationship between sheet bulk and internal strength in the middle ply can be further improved by surface modification of the CTMP fibers, e. g. by mixtures of cationic starch and CMC (Pettersson et al. 2006, Pettersson et al. 2015). However, to get very high strength on sheets from HYP, i. e. close to that from softwood kraft pulps, the high sheet bulk has to be reduced. If that reduction can be done at conditions where the advantageous relationship between in-plane strength and bulk is maintained, it will be very attractive to manufacture also paper products with very high requirements in term of strength characteristics, e. g. packaging papers, also from HYP containing webs.

Very high strength of papers from softwood CTMP can certainly be achieved at conventional papermaking conditions if its fibers are refined to sufficiently high flexibility, (Höglund and Bodin 1976). However, this is, unfortunately, extremely energy demanding, (Klinga et al. 2008). The energy consumption is on such high level that it up to now has not been of interest to use CTMP in paper products with very high requirements upon strength out of economical reasons. To be able to manufacture strong papers from HYP in an economical feasible way, the conventional conditions in papermaking have to be changed to take advantage of the specific characteristics of lignin rich fibers. It might then be possible to use even such HYP fibers, which have been manufactured at very low consumption of electric energy in manufacturing of strong papers.

As will be described below, it is known that the strength of HYP containing papers can be improved significantly by changing conditions away from the conventional ones in at pressing and drying in papermaking. At 
press temperatures below the softening temperature of lignin an enhanced pressure seems to have the greatest impact on sheet strength, but the effect of press temperature is also significant (Chagaev et al. 1999, Nygren et al. 2003). Accordingly, it has been shown that at densification of CTMP based moist sheets in a press nip at high pressure, the tensile strength can be improved by $10-15 \%$ by increasing the press temperature from 25 to $100^{\circ} \mathrm{C}$ (Pettersson et al. 2017). In that investigation it was also shown that sheet tensile strength close to that from kraft pulps can be achieved from a furnish of spruce CTMP fibers that have been surface modified with a mixture of cationic starch/CMC and reinforced with $20 \%$ kraft pulp. However, if the nip press temperature would be increased above the softening temperatures of lignin (Goring 1963, Höglund et al. 1976, Salmén 1984, Irving 1985), the effect of densification of lignin rich webs was predicted to be even much higher (Pettersson et al. 2017).

The positive effect on strength of increased web temperature in press-drying of paper and paperboard webs is well known since a long time (Karlsson and Paltakari 2008). The technique was in special focus in the 1970s. In press-drying paper can be fully dried under restrain due to an applied pressure in the Z-direction, while the paper is in contact with hot surfaces with a temperature well over the softening temperature of lignin, (Michell 1984). At these temperatures moist hemicellulose and lignin in the fibre walls of high yield pulps, e. g. CTMP, is softened (Back and Salmén 1982). Moist lignin becomes tacky and bond strength between fibers with lignin containing surfaces in close contact is improved (Gupta et al. 1962, Pynnönen et al. 2002). Lehtinen developed the press-drying concept into a continuously working process, the so called Condebelt drying process (Lehtinen 1984, Lehtinen 1995). In that process the paper web is fed between two steel belts. The belt on top is heated and water cools the belt under the web, where the evaporated steam from the paper web condenses and is transported out of the press-drying unit. To get good strength properties, paper sheet temperature of about $140^{\circ} \mathrm{C}$ is reported to be needed, i. e. a temperature above the softening temperature of lignin. Typically, sheet is press-dried in the dryness interval 55-80\% (Schlegel et al. 1999).

In Impulse Drying, another high temperature drying concept that has been in focus off and on during a long period, water is removed from the paper web in a hot nip press on the paper machine by the combined action of mechanical pressure and intense heat $\left(\mathrm{T}>200^{\circ} \mathrm{C}\right.$ ), (Arenander and Wahren 1983). A serious problem associated with the Impulse Drying technique, which has been the main obstacle for commercialization, is that delamination easily occurs when superheated water flashes into vapour after the hot press nip (Orloff and Sobczynski 1993).

Also, some other alternative paper drying concepts, where higher temperatures than conventional is used, have more recently been proposed (Karlsson and Paltakari 2008).

A common experience from full scale or pilot plant installations, where a high z-directional pressure is applied in combination with a temperature above the softening temperature of lignin, is that paper strength and paper smoothness are improved. Quality improvements are more obvious with furnishes containing pulps with a high content of lignin, like CTMP.

\section{Object of the study}

In the current paper a study is reported where moist sheets ( $40 \%$ d.c.) of spruce HT-CTMP and CTMP are densified in a hot press nip at nip temperatures above the lignin softening temperature. The effect of fiber surface modification of the CTMP fibers with a low dosage of cationic starch was studied as well. The main objective of the study was to find conditions, which make it possibility to enhance tensile strength, tensile stiffness and compression strength (SCT) from spruce HT-CTMP and CTMP sheets up to the same level as is common from chemical pulp furnishes.

\section{Materials and methods}

\section{Pulp preparation}

For the trials in this study, a special low energy, high freeness (CSF $720 \mathrm{ml}$, fiber length 2,2 mm) HT-CTMP from spruce $(600 \mathrm{kWh} /$ adt in refining stages including reject refining) was manufactured in a mill trial performed at the SCA Östrand CTMP mill in Timrå, Sweden. In the mill the impregnation vessel is situated inside the preheater and chips are atmospherically steamed before impregnation with $15-20 \mathrm{~kg} \mathrm{Na}_{2} \mathrm{SO}_{3}$ at $\mathrm{pH} 10$. Preheating temperature was about $170^{\circ} \mathrm{C}$. A feeding type of turbine refiner plates was used in the main refiner. The pulp was peroxide bleached and flash dried. A standard type of bleached flash dried spruce CTMP (CSF $420 \mathrm{ml}$, fiber length 1,9 mm) from the same mill was also used $(950 \mathrm{kWh} /$ adt in refining stages including reject refining). A standard market bleached softwood kraft pulp, also from the SCA Östrand mill, was tested as a reference pulp. The unbleached softwood kraft pulp was circulation refined at $4 \%$ consistency 
in a Voith Sulzer LR1 laboratory refiner with conical refiner fillings. Fibres were beaten to $25 \mathrm{SR}$ and the unbeaten kraft pulp had a fibre length of $2.2 \mathrm{~mm}$.

Before sheet making, HT-CTMP and CTMP were hot disintegrated according to SCAN M10:77 and the bleached softwood kraft pulp were reslushed according to SCAN C: 1865.

Fibers in some HT-CTMP and CTMP trials were treated with cationic starch $(25 \mathrm{mg} / \mathrm{g})$ at room temperature, $\mathrm{pH}$ around 7 . The starch was allowed to adsorb for $2 \mathrm{~min}$ during mixing with air bubbles before sheets were made on the sheet former.

\section{Chemicals}

Potato starch, CS, supplied by Lyckeby Starch Ab, Sweden, with a cationic degree of substitution of 0.040 was used. The starch was laboratory cooked by heating a $5 \mathrm{~g} / \mathrm{l} \mathrm{starch}$ slurry to $95^{\circ} \mathrm{C}$, maintaining this temperature for $30 \mathrm{~min}$ and allowing the starch solution to cool down under ambient conditions. Fresh solutions of starch were prepared every day in order to avoid the influence of starch degradation.

\section{Sheet preparation to $40 \%$ d.c. in laboratory}

Sheets were made on a Rapid Köthen sheet former from Paper Testing Instruments (PTI), Pettenbach, Austria. Sheets with a grammage of $150 \mathrm{~g} / \mathrm{m}^{2}$ were formed after vigorous aeration of the fibre suspension just before sheet preparation. The sheets were then press-dried at $100 \mathrm{kPa}$ pressure under restrained conditions at $94^{\circ} \mathrm{C}$ until $40 \%$ dryness content was achieved. After that the sheets were stored in plastic bags in a refrigerator for about $24 \mathrm{~h}$ before transportation to More Research in Örnsköldsvik, where the sheets were finally pressed and dried on a drying cylinder equipped with a felted press nip, Figure 1.

\section{Press drying equipment}

The moist sheets were inserted on the fabric between a press roll and a heated cylinder of the pilot press drying machine, Figure 1 . The diameter of the cylinder and the press roll was $0.8 \mathrm{~m}$ and $0.2 \mathrm{~m}$ respectively. The feeding rate was $1 \mathrm{~m} / \mathrm{min}$. The nip pressure was on a constant high level, which was selected to give sheets with high densities (The effects of different combinations of high temperatures and nip pressures will be reported in detail the next paper in the series "Strong paper from spruce CTMP"). The cylin-

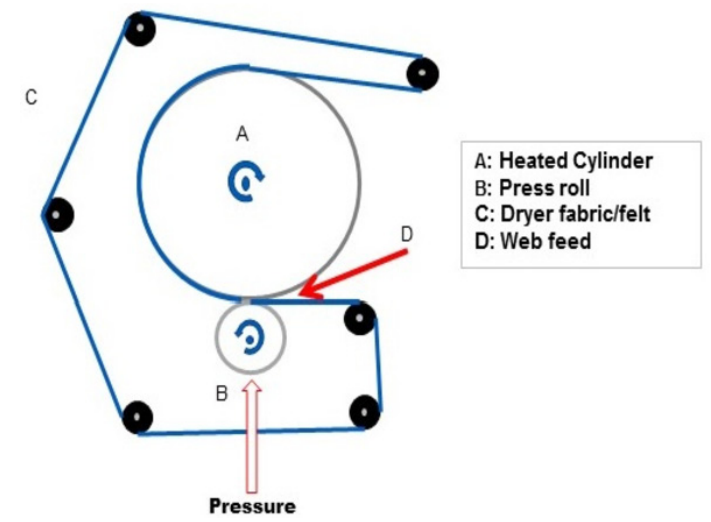

Figure 1: The press drying equipment at MoRe Research in Örnsköldsvik.

der temperature was varied between $20-200^{\circ} \mathrm{C}$. The press nip duration was about one second. The sheets, which were pressed at $20^{\circ} \mathrm{C}$, were thereafter fed into the dryer a second time without applied press load for final drying of the sheets at $100^{\circ} \mathrm{C}$ cylinder temperature. The sheets that were pressed and dried at $100-200^{\circ} \mathrm{C}$ reached full dryness during the first loop.

\section{Sheet testing}

Sheet testing was carried out after conditioning (ISO 187). Tensile testing was conducted according to ISO 5270/ 1924-3, which also includes the method for testing tensile stiffness. SCT was measured according to ISO 5270 and grammage, thickness and density were evaluated according to ISO 5270.

The coefficient of variation in testing of the different paper properties was approximatively $3 \%$ (density), $7 \%$ (tensile index), $8 \%$ (elongation of failure), $6 \%$ (SCT) and $5 \%$ (tensile stiffness and E-modulus).

\section{Results and discussion}

In the current study, sheets from the medium freeness ( $420 \mathrm{ml})$ CTMP and the high freeness $(720 \mathrm{ml})$ HT-CTMP were pressed in the hot press nip at cylinder temperatures above the softening temperature of lignin. The effects of sheet properties were compared with those of the laboratory beaten bleached kraft pulp. Furthermore, the effect of surface modification of HT-CTMP and CTMP fibers with just a low dosage of cationic starch was evaluated. As the HT-CTMP and CTMP fibers are rather stiff and the fine material contents in these types of pulps is very low (Höglund 
and Wilhelmsson 1992), the sheets from these pulps have a more open structure than sheets from chemical pulps. This might be a key advantage to be able to evacuate steam through the sheet after densification in hot press nips without delamination of the sheet structure, which has been the serious problem in attempts to commercialize impulse drying technology. The dry content of sheets fed into the press nip was approximately $40 \%$ throughout the whole study. This dry content was selected to be able to demonstrate the full potential of pressdrying in the selected temperature range. A somewhat higher dry content would naturally be an advantage as a lower amount of steam then has to be evacuation. Previous studies have shown that sheet from high freeness HYP are most efficiently consolidated to a fix structure during press-drying in the dry content interval between 50-75\%, (Klinga et al. 2007, Norgren and Höglund 2014). Therefore a somewhat higher sheet dryness at feeding into the press nip should presumably not negatively affect the strength improvements that is found in the current study. This statement is also supported by results from pressing sheets with different initial dryness at press cylinder temperatures below the lignin softening temperature in the same press and drying equipment as in this study (Pettersson et al. 2017).

\section{Densification}

The densification effects on sheet structures as a result of increased press nip temperature is shown Figure 2. The effect is very pronounced for sheets containing untreated HT-CTMP and CTMP fibres, i. e. the sheets containing lignin rich fibers, whereas sheets from the kraft pulp are less affected of the press temperature, Figure 2a. The relative increase in density is largest on sheets from the high freeness HT-CTMP, where the density is more than doubled, when the press nip temperature is increased from 20 to $200^{\circ} \mathrm{C}$. A sheet density close to that of the kraft pulp sheets is obtained at a press nip temperature of $200^{\circ} \mathrm{C}$. Obviously, the softening of the HYP fibres makes it possible to bring the fiber material in close contact and permanent strong fiber-fiber bonds are created at the present conditions, i. e. pressure at press nip temperatures above the softening temperature of lignin at suitable moisture content. It is known from other studies that if the press and drying stages is carried out in a too low dry content range, compressed stiff HYP fibers easily spring back to their original shapes when the pressure is released, since creation of permanent fiber-fiber bonds are prevented by water between fiber surfaces in the paper sheet, (Klinga et al. 2007, Norgren and Höglund 2014). On the other hand, if the dry content is too high, i. e. above the wet saturation point of the fiber material, strong permanent fiber-fiber bonds are not established in paper structures.

After fiber surface modification of the high yield fibers with cationic starch the densification effect is very similar to that without surface treatments, Figure 2b. Thus, the densification effect is not significantly higher.

\section{Improvement of tensile Index}

With increased density, due to higher temperature in pressing and drying, the tensile index of HYP sheets are substantially improved. Figure 3. Sheets from CTMP (CSF $420 \mathrm{ml}$ ), where the fibers have been surface treated with cationic starch, reach tensile index at the same level as the untreated reference kraft pulp at the highest press temper-

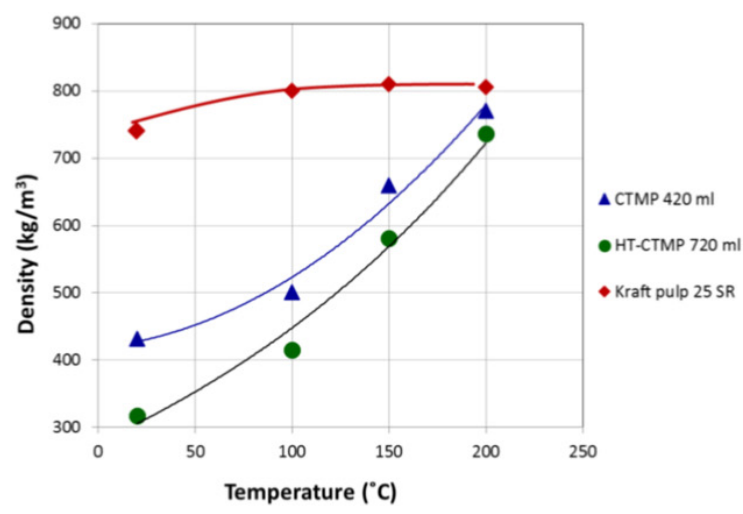

$2 \mathrm{a}$

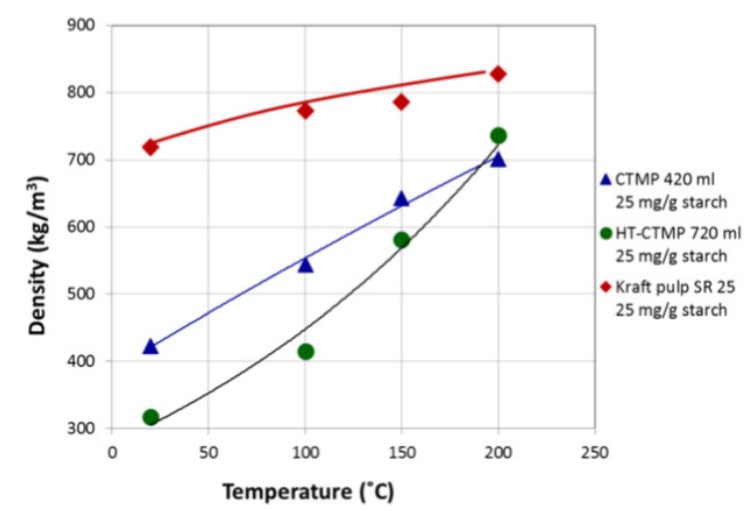

$2 \mathrm{~b}$

Figure 2: Density versus press nip temperature of sheets made from two different spruce HT-CTMP and CTMP (CSF $720 \mathrm{ml}$ and $420 \mathrm{ml}$ respectively) and a kraft pulp ( 25 SR). In Figure $2 \mathrm{~b}$ the fibers were treated with $25 \mathrm{mg} / \mathrm{g}$ starch. 


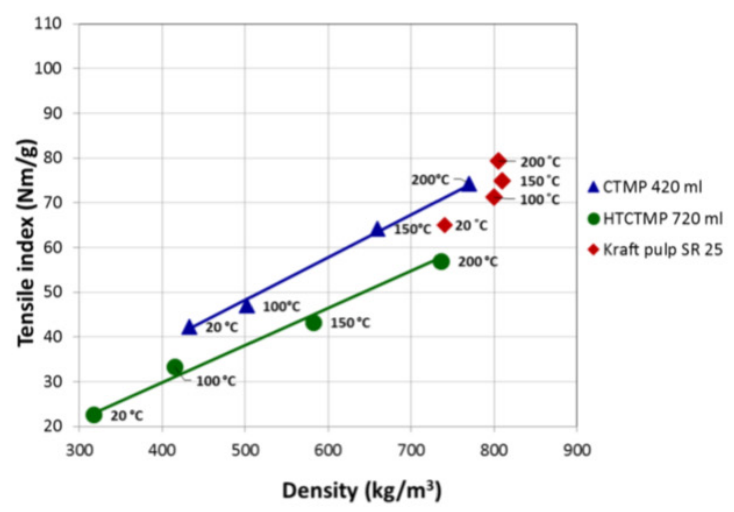

$3 a$

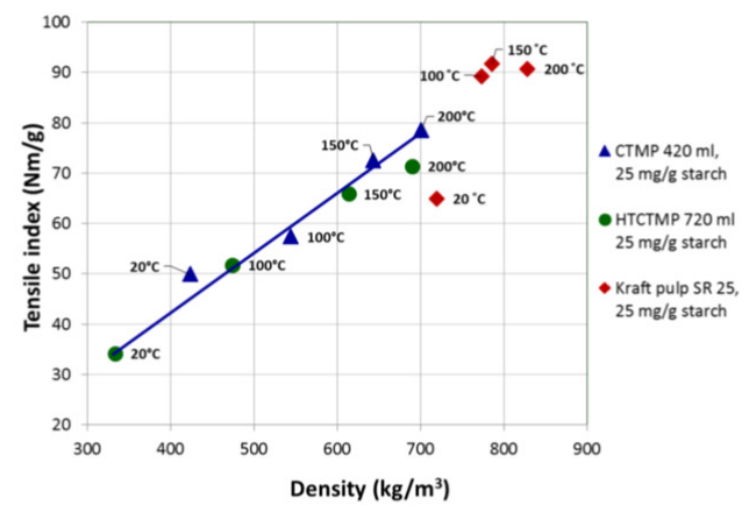

$3 b$

Figure 3: Tensile index versus sheet density of sheets made from two different spruce HT-CTMP and CTMP pulps (CSF $720 \mathrm{ml}$ and $420 \mathrm{ml}$ respectively) and a kraft pulp ( $25 \mathrm{SR})$. In Figure $3 \mathrm{~b}$ the sheets fibers were treated with $25 \mathrm{mg} / \mathrm{g}$ starch. Press nip temperatures are indicated.

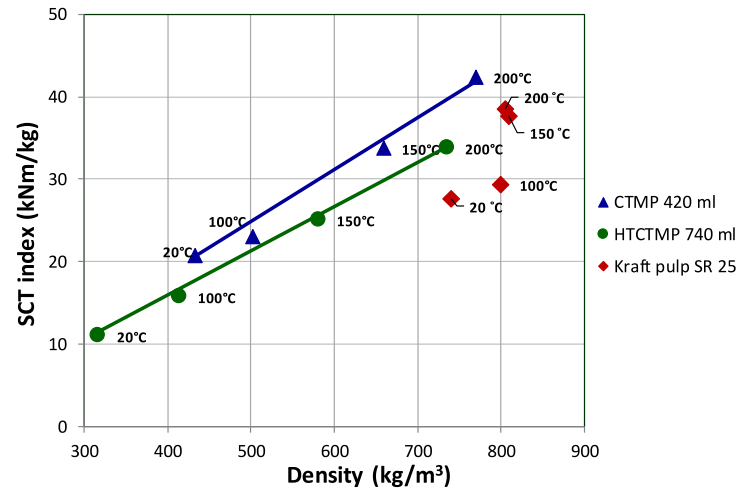

$4 a$

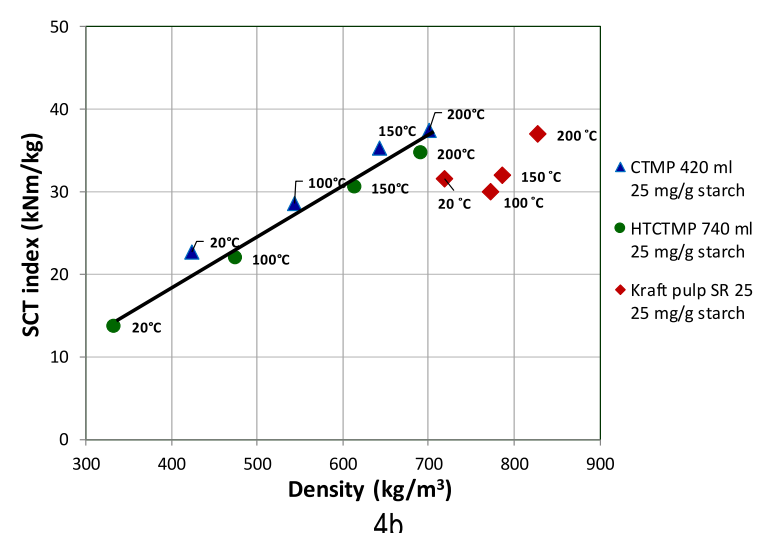

$4 b$

Figure 4: Compression index (SCT) versus sheet density of sheets made from two different spruce HT-CTMP and CTMP pulps (CSF $720 \mathrm{ml}$ and $420 \mathrm{ml}$ respectively) and a kraft pulp ( $25 \mathrm{SR}$ ). In Figure $4 \mathrm{~b}$ the fibers were treated with $25 \mathrm{mg} / \mathrm{g}$ starch. Press nip temperatures are indicated.

ature. Even the surface treated HT-CTMP, which has been manufactured with an electric energy consumption in refining of just $600 \mathrm{kWh} / \mathrm{ton}$, reached almost that level. The bond strength in the lignin rich sheet structure is obvious very high and certainly related to that the moist lignin has got very tacky at the enhanced temperature. As the number of fibers in the HT-CTMP or CTMP webs is just about half of that in the kraft pulp sheets, due to the difference in pulp yields, the strength of fiber-fiber bonds between the lignin rich fibers might be even higher than fiber-fiber bonds between bleached kraft pulp fibers.

\section{Improvements of compression strength (SCT)}

The best compression strengths of CTMP as well as HTCTMP sheets, which have been achieved at the highest press nip temperature, is on a very high level, Figure 4. This is not surprising as the density and tensile index of the spruce HT-CTMP and CTMP sheets, which have been pressed at the highest press nip temperature, are quite similar to the kraft pulp reference sheets. Compression index for the HYP sheets should then be as high as or higher than the kraft pulp sheets as the HYP fibers are much stiffer.

\section{Improvements in tensile stiffness}

The development of tensile stiffness for HT-CTMP and CTMP sheets with increased press temperature, follows almost the same pattern as for tensile index and tensile stiffness, Figure 5. It is obvious that it is possible to reach the same level of tensile stiffness of HYP sheets as for the reference sheets from the kraft pulp. Except for in different kind of packaging paper applications, a high tensile stiffness is a valuable property also in outer layers of multilayer packaging board as discussed in the background section (Bengtsson 2005, Fellers et al. 1983). 


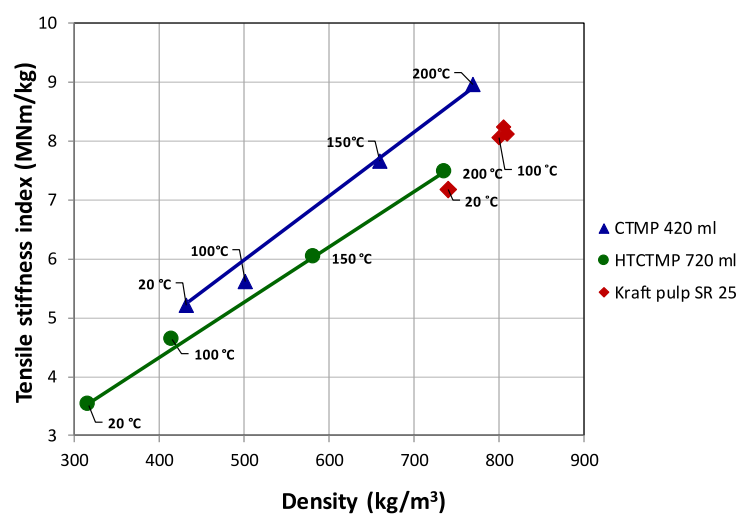

$5 a$

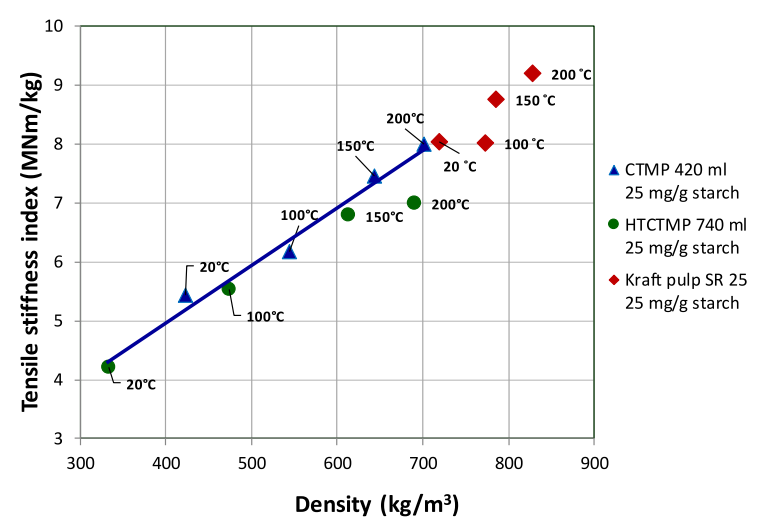

$5 b$

Figure 5: Tensile stiffness versus sheet density of sheets made from two different HT-CTMP and CTMP pulps (CSF $720 \mathrm{ml}$ and $420 \mathrm{ml}$ respectively) and a kraft pulp ( 25 SR). In Figure $5 \mathrm{~b}$ the fibers were treated with $25 \mathrm{mg} / \mathrm{g}$ starch. Press nip temperatures are indicated.

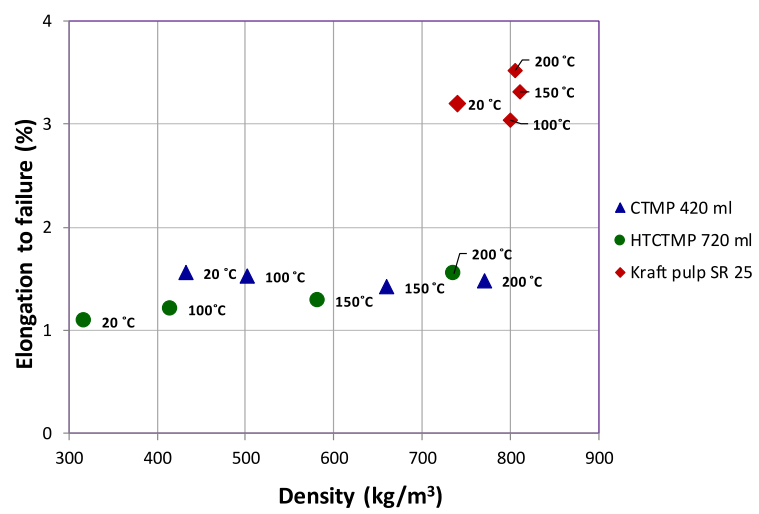

$6 a$

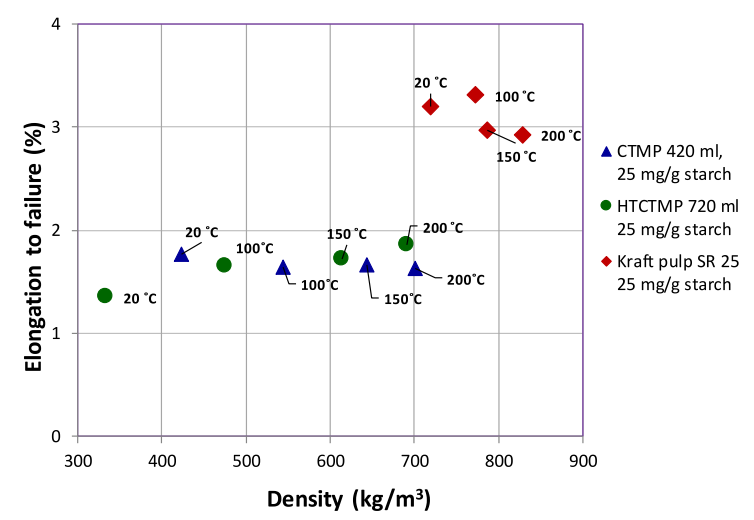

$6 \mathrm{~b}$

Figure 6: Elongation to failure versus sheet density of sheets made from two different HT-CTMP and CTMP pulps (CSF $720 \mathrm{ml}$ and $420 \mathrm{ml}$ respectively) and a kraft pulp ( $25 \mathrm{SR}$ ). In Figure $3 \mathrm{~b}$ the fibers were treated with $25 \mathrm{mg} / \mathrm{g}$ starch. Press nip temperatures are indicated.

\section{Elongation to failure}

Elongation to failure is generally significantly lower of HYP sheets than for sheets containing flexible kraft pulp fibers, which might be a disadvantage in some product applications, Figure 6. However, for HT-CTMP the elongation at failure seems to be improved somewhat, when the press temperature is increased. Treatments with starch have also a positive impact.

\section{Concluding remarks}

This study show that it is possible to manufacture sheets from spruce CTMP with tensile index, compression index (SCT) and tensile stiffness at the same level as that of sheets from a bleached softwood kraft pulp, when conditions in papermaking are changed to better suit the characteristics of lignin rich HYP fibers. It is evident that HYP webs can be consolidated to a dense and strong structure, when sheets are fed at about $40 \%$ dry content into a hot press nip, where the temperature is above the softening temperature of lignin. At such condition in papermaking even HYP like HT-CTMP, which can be manufactured at very low consumption of electric energy in refining, might be possible to utilize in manufacturing of paper product with high requirements upon strength, e.g. packaging papers.

In this study, sheets are densified in a press nip between a press roll and a hot cylinder. Temperatures up to $200^{\circ} \mathrm{C}$ on the hot cylinder were tested. The nip duration was about $1 \mathrm{~s}$. Even during the final drying, the sheets were in contact with the heated cylinder. These conditions were evidently sufficient to reach temperatures above the softening temperature of lignin also in the sheet structures. If not, the lignin on the fiber surfaces would not be soft and tacky, which seems to be a prerequisite to get very high bond strength between HYP fibers (Goring 1963, Gupta 
et al. 1962). The results indicate that sheet properties may be further improved if even higher temperatures than used in this study are utilized. This will certainly also be necessary at paper machine conditions, where the press duration will be much shorter. To reach the effects regarding paper strength improvements, which have been shown in this study, the sheets must be heated to a temperature well above the lignin softening temperature. As lignin is a viscoelastic material, its softening temperature increases with increased loading rate (Höglund et al. 1976, Salmén 1984, Irving 1985). Sufficiently high press temperatures to reach the lignin softening temperature in the paper structure on a full scale paper machine will therefore depend on both press design and paper machine speed.

The results in this study show that there is a yet unexploited potential of spruce HT-CTMP and CTMP, which could be utilized in manufacturing of products besides the traditionally ones, i. e. graphic papers and paperboard products, where very high requirements upon strength is demanded. Sheet characteristics from HYP webs can be changed within a broad range, as the physical and chemical properties of lignin are marked different at varying temperatures. To be able to form sheets at high densities from HYP webs in a cost-efficient way, it is evident that lignin has to be softened to temperatures well above the softening temperatures of lignin.

More detailed studies of changes in HYP sheet structures and fiber-fiber bond mechanisms related to different press temperatures above the lignin softening temperature will be reported in papers to follow this one.

\section{Conclusions}

Tensile strength, tensile stiffness and compression strength (SCT) of sheets from spruce HT-CTMP and CTMP can be enhanced up to the same level as is common on sheets from bleached chemical pulp furnishes, when moist sheet structures ( $40 \%$ d.c.) are densified by pressing at press nip temperatures well above the tack and softening temperatures of lignin. For instance;

- Sheets from CTMP (CSF $420 \mathrm{ml}$ ), where the fibers are surface treated with cationic starch, reach tensile index of about $80 \mathrm{Nm} / \mathrm{g}$, which is on the same level as on sheets from a typical bleach kraft pulp ( $\left.25^{\circ} \mathrm{SR}\right)$.

- Compression index of $35-40 \mathrm{kNm} / \mathrm{kg}$ on sheets from HT-CTMP (CSF $720 \mathrm{ml}$ ) and CTMP (CSF $420 \mathrm{ml}$ ) can be reached, which is as high as or higher than of sheets from a typical bleached kraft pulp ( $\left.25^{\circ} \mathrm{SR}\right)$.
- $\quad$ Sheets from CTMP (CSF $420 \mathrm{ml}$ ) reach tensile stiffness of $9 \mathrm{MNm} / \mathrm{kg}$, which seems to be higher than of sheets from a typical bleached kraft pulp (25 $\mathrm{SR})$

The results show that there is a great yet unexploited potential in papermaking from spruce HT-CTMP and CTMP furnishes, which could be utilized in manufacturing of products where very high requirements upon strength is demanded.

Acknowledgments: The authors would like to thank personnel at More $\mathrm{AB}$ for the good cooperation during their experimental work in Örnsköldsvik.

Funding: The Swedish Energy Agency, the Knowledge Foundation, Troëdssons Foundation and the Åforsk Foundation are gratefully acknowledged for their financial support.

Conflict of interest statement: The authors do not have any conflicts of interest to declare.

\section{References}

Arenander, S., Wahren, D. (1983) Impulse drying adds new dimension to water removal. Tappi 66(9):123-126.

Back, E.L., Salmén, L. (1982) Glass transitions of wood components hold implications for molding and pulping processes. Tappi 65(7):107-110.

Bengtsson, G. (2005) CTMP in production of high quality packaging board. In: Proc. International Mechanical Pulping Conference, Oslo. pp. 7-13.

Chagaev, O., Stationwala, M., Allem, R. (1999) The role of fiber collapse in mechanical pulping. In: Proc. International Mechanical Pulping Conference, Houston. pp. 155-169.

Fellers, C., de Ruvo, A., Htun, M., Calsson, L., Engman, C., Lundberg, R. (1983) In Carton Board, Swedish Forest Products Research Laboratory, Stockholm, Sweden.

Fineman, I. (1985) Let the paper product guide the choice of mechanical pulp. In: Proc. International Mechanical Pulping Conference, Stockholm, pp. 203-214.

Goring, D. (1963) Thermal softening of lignin, hemicellulose and cellulose. Pulp Pap. Can. 64(12):T517-T527.

Gupta, P.R., Pezanowich, A. Goring, D. (1962) The adhesive properties of lignin. Pulp Pap. Can. 63(1):T21-T31.

Höglund, H., Bodin, O. (1976) Modified thermo-mechanical pulp. Svensk Papperstidn. 79(11):343-347.

Höglund, H., Sohlin, U., Tistad, G. (1976) Physical properties of wood in relation to chip refining. Tappi 59(6):144-147.

Höglund, H., Wilhelmsson, K. (1992) The product must determine the choice of wood type in mechanical pulping. In: Proc. International Mechanical Pulping Conference, Oslo. pp.1-22.

Irving, G.M. (1985) The significance of the glass transition of lignin in thermomechanical pulping. Wood Sci. Technol. 19:139-149. 
Karlsson, M., Paltakari, J. (2008) Introduction to paper drying and its principles. In: Papermaking Science and Technology. Ed. Karlsson, M. Book 9, (Papermaking Part 2, Drying, Chapter 1), Fapet Oy, Helsinki. pp. 27-31.

Klinga, N., Höglund, H., Sandberg, C. (2007) Paper properties of TMP and CTMP handsheets from spruce, as affected by solid content from pressing. Nord. Pulp Pap. Res. J. 22(4):475-480.

Klinga, N., Höglund, H., Sandberg, C. (2008) Energy efficient high quality CTMP for paperboard. J. Pulp Pap. Sci. 34(2):98-106.

Lehtinen, J.A. (1984) Method of continuous drying of a paper or other porous web and a drying device for applying this method, USA Patent No. 4,461095.

Lehtinen, J.A. (1995) Condebelt drying: Quality results and process development. Pap. Technol. 36(10):67-71.

Michell, A.J. (1984) Press drying of paper - An overview. Appita J. 37(4):325-329.

Norgren, S., Höglund, H. (2014) Consolidation of fibre-fibre bonds in TMP and CTMP based papers. Pap. Technol. 55(3):6-10.

Nygren, O., Bäck, R., Höglund, H. (2003) On characterization of mechanical and chemimechanical pulps. In: Proc. International Mechanical Pulping Conference, Quebec City, pp. 97-104.

Orloff, D.I., Sobczynski, S.F. (1993) Impulse drying pilot press demonstration: Ceramic surfaces inhibit delamination. Pap. Technol. 34(10):24-32.
Pettersson, G., Höglund, H., Sjöberg, J., Peng, F., Bergström, J., Solberg, D., Norgren, S., Hallgren, H., Moberg, A., Ljungqvist, C.-H. (2015) Strong and bulky paperboard sheets from surface modified CTMP, manufactured at low energy. Nord. Pulp Pap. Res. J. 30(2:318-324.

Pettersson, G., Höglund, H., Wågberg, L. (2006) The use of polyelectrolyte multilayers of cationic starch and CMC to enhance strength properties of papers formed from mixtures of unbleached chemical pulp and CTMP. Nord. Pulp Pap. Res. J. 21(1):115-128.

Pettersson, G., Norgren, S., Höglund, H. (2017) Strong paper from spruce CTMP. Part I. Nord. Pulp Pap. Res. J. 32(1):54-58.

Pynnönen, T., Hiltunen, E., Paltakari, J., Laine, J.E., Paulapuro, H. (2002) Good bonding for low-energy HT-CTMP by press drying. Pulp Pap. Can. 105(3):T57-T61.

Salmén, L. (1984) Viscoelastic properties of in situ lignin under water saturated conditions. J. Mater. Sci. 19:3090-3096.

Schlegel, J., Rökman, B., Saari, J. (1999) Condebelt drying Board properties BM clothing and runnability. Pap. Technol. 40(10):29-41. 